\title{
6 The Family and Adolescent Issues
}

In the previous chapter we looked at some of the potential outcomes of parental divorce for adolescents. In this chapter we explore more fully a range of family issues that can affect the outcomes and behaviours of adolescents.

Conflict with parents is common in adolescence, and some would suggest that it is essential. At least in early adolescence, conflict is relatively common, and moderate conflict between parents and adolescents seems to be linked to better psychological adjustment than high or no conflict (Adams \& Laursen, 2001). Conflict seems to be important to successful individuation, as relationships between parents and adolescents are transformed and adolescents obtain a stronger sense of their own identity and the need for more control over their lives (see also Chapter 2 on individuation). Adolescents can also experience negative mood states as they move through this stage of their lives (Larson, Moneta, Richards \& Wilson, 2002) and these negative moods can have an impact on the whole family.

One of the major concerns of parents of adolescents is the problem behaviour that adolescents can become involved in. It's important to remember, however, that most adolescents do not become involved in seriously problematic behaviour. Most adolescents find other more appropriate ways to exert their independence, which is very important at this stage of life, although not always welcomed by parents. Many people believe, rightly so, that adolescents tend to get a bad press. One issue is that the media continually focus on a small number of 'bad apples' and ignore the positive behaviour of most adolescents.

While acknowledging that adolescents do tend to get an unnecessarily bad press and that negative stereotypes are rife in the media, it is nevertheless important to recognise that there are a lot of potential traps for adolescents involved in youth culture in the $21^{\text {st }}$ century. In addition, getting involved in these problem behaviours may have implications for the rest of a teenager's life. Probably the issues that concern parents most are drug abuse and teenage pregnancy, because both of these problems have far-reaching consequences, affecting educational opportunities, employment possibilities, romantic and family relationships and, particularly in the case of drug abuse, health.

In this chapter, we explore research on a range of potential problem behaviours including involvement in alcohol and illegal drugs, smoking, issues around sexuality such as early sexual involvement, teenage pregnancy and sexually-transmitted diseases, depression and suicidal behaviour, eating disorders, and conduct disorder, aggression and delinquency. In each case, we explore family factors that are likely to increase or decrease the probability that young people will become involved in these behaviours. In exploring these issues, we will be seeking to highlight the contexts in which the problems are likely to arise and look for ways they might be avoided. Our hope is that many of these problems will be avoided as parents and other adolescent workers become more aware of the ways these problems can be prevented. 
It seems very clear that parents' positive involvement with their adolescents is critical to the promotion of healthy behaviours among adolescents and provides a protective effect against involvement in risky behaviours (Wange, Hsu, Lin, Cheng, \& Lee, 2009). The positive effects have been found for alcohol use (Kumpfer \& Alvarado, 2003), unprotected sexual intercourse (Resnick, Bearman, Blum, Bauman et al., 1997) and also for involvement in illegal drugs such as marijuana and cannabis (Kumpfer \& Alvarado, 2003).

\subsection{Positive Youth Development}

Before looking at specific behaviours, it is important to acknowledge, as we did in Chapter 2, the growth of interest in Positive Youth Development (PYD; Hamilton et al., 2004) and the programs that have been produced in response to this framework (Bradshaw et al., 2008). PYD has been influenced by the positive psychology movement (Seligman \& Csikszentmihalyi (2000). The key principles of PYD include an emphasis on making programmes available to all who want to be involved rather than targeting those with known problem behaviours, and promoting resilience, rather than problem-prevention or treatment. There is also a focus on building relationships with caring people through involvement in challenging activities and on youth as active rather than passive recipients of services (Hamilton et al., 2004). The model also emphasizes that adolescents should be provided with opportunities that enable them to build on their assets rather than focus on their risks (Damon et al., 2004).

PYD programs seem to have developed in response to the many negative stereotypes of adolescents that are common, at least in Western societies. As Larson (2006) notes "there has been growing recognition that young people are more than soft clay to be moulded ... Rather, young people are motivated and able to be constructive agents of their own development” (p. 677). In his Presidential Address to the Society for Research in Adolescence, Reed Larson (2010) again put an emphasis on the importance of adolescents developing a sense of agency that can help them to work toward "goals in real-world contexts" (p. 317). He claims that the relevant competencies (emotional, motivational and cognitive/ecological) are even more important in the $21^{\text {st }}$ century than they have been in the past. He quotes Giddens' (1990) who argues that "living in the modern world is more like being aboard a careening juggernaut than being in a carefully controlled and well-driven motor car" (p.53), it is amazing that a statement made in 1990 could be so appropriate for the $21^{\text {st }}$ century with its continual and rapid change.

Nevertheless, as Bradshaw et al. (2008) point out, “advocates of the more positive and strength-based definitions of youth development must grapple with the reality of problem behaviour" (p. 211). Larson (2006) makes the point that most professionals involved with adolescents recognize that teenagers can be agents of their own 
growth, but can also be wilful in the negative sense of that word. He claims that currently there are a wide range of differing views about young people's agency and wilfulness, and that the dominant view among those who work with troubled adolescents is not necessarily as helpful as advocates of PYD would hope.

Smetana, Campione-Barr and Metzger (2006) acknowledge that parents tend to see adolescence as a particularly challenging time but also note that extreme alienation from parents, active rejection of adult values and authority and youthful rebellion are the exception, rather than the norm (Collins \& Laursen, 2004). Smetana et al. claim that only between 5 and 15 percent react in this extreme way. Nevertheless, it is important to recognise that this small minority do tend to be in the public eye because of their antisocial behaviour, and tend to contribute disproportionately to the negative stereotypes of adolescents. In addition, as we pointed out in the previous chapter, about half of parents report being unhappy about the behaviour of their adolescents in family situations.

In our attempt to grapple with the reality of youth problem behaviour, we acknowledge that about 60 percent of youth are likely to show some level of behaviour problems, although their behaviour generally tends to stay within the normative range (Moffitt, 2006). According to Moffitt, problem youth can be divided into three groups. The first group includes those young people who display problem behaviour only at adolescence (about 24 percent of all youth). These young people generally grow up to live productive lives. The second group includes those who have a history of problem behaviour beginning in preschool (5-6 percent of all youth).

National data on crime in the USA suggest that this latter group commit 50 percent of juvenile criminal acts (Snyder \& Sickmund, 2006) and for this reason it is important that psychologists, social workers and others who work with vulnerable young people understand these issues. A third group demonstrate problem behaviour as children but are more conforming as adolescents, although Moffitt and his colleagues (Moffitt, Caspi, Harrington, \& Milne, 2002) found that about a third of these young people suffered from internalizing problems such as depression and anxiety disorders. An important question for advocates of PYD is which of these groups of adolescents are most likely to be helped by their programs.

Problems that may confront adolescents can be divided into two broad groups: externalising behaviours, behaviours that can be seen, and internalizing behaviours, problems that are more internal to the person or hidden. As examples of the first type, we discuss involvement in alcohol and other drugs, smoking and sexual activity. As examples of the second type we discuss depression and suicide (as a consequence of depression) and eating disorders. 


\subsection{Externalizing Behaviours}

\subsubsection{Alcohol and Illegal Drugs}

According to Bonomo and Proimos (2005), the misuse of drugs such as alcohol, tobacco, inhalants and other drugs is now common among young people all over the world and such misuse causes a range of health problems in this group. Alcohol and other drugs can be a serious problem area for adolescents and their families and it seems clear from the research that the family environment plays an important part in adolescents' involvement in heavy drinking and illegal drugs. One concern is that many parents don't seem to realise the problems created for young people by heavy drinking, and tend to report being more concerned about the possibility of their teenagers using illicit drugs such as heroin than using alcohol (Taylor \& Carroll, 2001). Yet many other problem behaviours such as assaults, inappropriate sexual activity, speeding in control of a car, and various criminal activities are often alcohol-related (Windle, 1996). For example, in Australian society, there is presently concern at all levels of government about alcohol-fuelled violence, with young people even being killed as a result. In addition, heroin and other illicit drugs kill far fewer adolescents than alcohol and alcohol-related behaviours.

Baumrind and Moselle (1985) have suggested that substance use may negatively affect the ability of adolescents to deal with the age-appropriate normative developmental life tasks, discussed in Chapter 2. To recap, these tasks include achieving a stable personal identity, forming relationships with their peers and renegotiating their relationships with parents to achieve a better balance between autonomy and closeness in the family. Where adolescents fail to work through these age-appropriate life tasks, they may experience a delay in the development of optimal personal, cognitive and social skills, impeding their progress through adolescence and young adulthood. Such adolescents are less likely than their peers to develop the sense of agency needed to be productive members of society.

There are two separate but associated problem areas related to the use of alcohol in particular: under-age drinking and drinking too much even when past the legal age. With regard to under-age drinking, in an Australian sample, only $15 \%$ of a sample of 15-17 year old males and $11 \%$ of females claimed to have never had an alcoholic drink, despite the fact that all these young people were still under the legal age (18) for consuming alcohol in Australia. Nearly two-thirds of the sample had consumed alcohol in a home setting with an adult present who presumably approved the behaviour. In addition, some had drunk more than seven drinks the last time they had alcohol, again with an adult present (Taylor \& Carroll, 2001), suggesting that parents are not always as responsible as they might be.

Taylor and Carroll (2001) claimed that there is a reluctant acceptance of underage drinking amongst parents, who report feeling powerless and overwhelmed and uncertain of how to cope, even though they agree that teaching children about 
drinking is their responsibility. It is also important to note that parents are not the only family members to influence adolescent's drinking behaviour, as siblings also play a role (Catalano et al., 1992; Windle, 2000). With regard to parent involvement in adolescent consumption of alcohol, police in Queensland, Australia have been very concerned about the amount of alcohol, including spirits, provided by parents to young people going to a tourist destination such as the Gold Coast to celebrate the end of their school lives at Schoolies programs.

Song, Reboussin, Foley, Kaltenbach et al. (2009) explored the relevance of the type of community that adolescents live in to under-age drinking. These researchers found that after controlling for individual characteristics, certain types of community characteristics were associated with the prevalence of under-age drinking. The lowest levels of drinking were found in communities where there were higher employment rates, a larger number of married families, and a greater percentage of grandparents caring for the young people. Although the positive impact of high employment and married families is not surprising (see Chapter 3), the result for grandparents as carers is surprising, since those young people with grandparents as carers are likely to have parents on drugs or in prison and to have had disrupted childhoods because of these problems. Perhaps grandparents provide a kind of stability for these young people that they haven't known before (see also Chapter 5).

Another community factor found to affect alcohol use in adolescents is the perceived availability of alcohol, increasing the probability of both current and earlier use (Nargiso, Friend \& Florin, 2013), as well as their likelihood of encouraging others to use alcohol. These researchers also found that what the early adolescents in their study (Grade 7s) saw as normative had a strong effect on their alcohol use, in terms of both current and earlier use. Adolescents' perceptions of norms are likely to be affected by the peer group, family expectations and media. In this study, poor relationships with parents also affected current and anticipated alcohol use.

Windle (1996) established a typology of adolescent drinking that categorized young drinkers into five types depending on the quantity and frequency of alcohol consumption, along with the extent to which the adolescent was involved in heavy-drinking episodes and suffered from alcohol-related adverse consequences. The five categories obtained were: abstainers, light drinkers, moderate drinkers, heavy drinkers and problem drinkers (see Table 6.1). The problem-drinking young people were more likely to come from families where at least one parent was an alcoholic (see also Jacob \& Windle, 2000), to have displayed high levels of childhood behaviour problems and to be currently involved in delinquent activities. They also reported lower levels of support from their families, and greater involvement with heavy-drinking peers. Parents who drink alcohol responsibly, monitor their children's behaviour and provide high levels of support are likely to have adolescents who do not become involved in problem-drinking. 
Table 6.1: Typology of Adolescent Drinking

\begin{tabular}{ll}
\hline Type of Drinker & Characteristics \\
\hline Abstainer & Did not drink alcohol \\
Light drinkers & Drank a small amount of alcohol on an irregular basis \\
Moderate drinkers & Drank moderate amount of alcohol regularly \\
Heavy drinkers & Drank a lot of alcohol but without problems experienced by problem- \\
& drinking peers \\
Problem drinkers & Problems related to drinking such as missing school because of drinking \\
& or passing out \\
& More likely to come from families with an alcoholic parent \\
& High levels of childhood behaviour problems \\
& Involved in delinquent activities \\
& Lower levels of support from families \\
& Greater involvement with drug-using peers \\
& Poor impulse control \\
\hline
\end{tabular}

Problem drinkers also tend to be different from their peers in terms of such dispositional characteristics as poor impulse control and sensation seeking (Windle, 1996). In addition, adolescents with difficult temperaments, who receive little or no parental monitoring and who are involved with drug-using peer networks are more likely to increase their substance use over time (Baumrind \& Moselle, 1985; Windle \& Windle, 2003).

The importance of parental monitoring of adolescents with regard to their behaviour with alcohol is also emphasized by Hayes, Smart, Toumbourou and Sanson (2004). They found that Australian adolescents who are appropriately monitored by parents begin drinking alcohol at a later age, are likely to drink less, and develop responsible drinking patterns. Given the findings reported earlier about the impact of poor parent-child relationships on alcohol use (Nargiso et al., 2013), it would seem likely that such young people would be less likely to respond well to parental monitoring. Of course, it is important to keep in mind that adolescents' perceptions of parental behaviour rather than actual behaviour were assessed in this study and these different types of data do not always lead to similar findings (Cohen \& Rice, 1997).

In a questionnaire study of over 400 Dutch families that involved both parents and two adolescents, Van der Vorst and colleagues (2005) found that when parents confidently applied strict rules about adolescents' alcohol use, their alcohol use tended to be lower. On the other hand, when there was a lot of communication about alcohol issues (perhaps nagging) adolescents consumed more alcohol. This finding applied, irrespective of the age of the adolescents (Van der Vorst, Engels, Meeus, Dekovic, \& Van Leeuwe, 2005). 
In another study where the aim of the researchers was to explore the associations among family environment, adolescent alcohol use, self-efficacy, peer influence and stress in a large sample of high-school students, the importance of the parents' role was again supported. Greater parental disapproval of the use of alcohol by their adolescents tended to be associated with less involvement with friends who used alcohol, and hence less peer influence to use alcohol. Adolescents in these families also had a greater sense of self-efficacy for avoiding alcohol use and hence fewer problems related to alcohol (Nash, McQueen \& Bray, 2005). This finding underlines the importance of the family environment to adolescents' alcohol use and supports the importance of positive parenting as helping young people develop confidence and self-efficacy (or agency) for dealing with alcohol problems. Perhaps the most important focus for prevention programs should be an emphasis on parents being able to set appropriate limits on their adolescents' alcohol consumption in a climate of positive parent-adolescent relationships (Varvil-Weld, Crowley, Turrisi, Greenberg \& Mallet (2013).

The findings of the Nash et al. (2005) study are supported by another Dutch study involving a large sample of adolescents who were still in high school. Adolescents were less likely to get involved in heavy drinking if their parents applied strict rules about drinking and the family members were able to have constructive conversations about drinking behaviour (Spikerman, van den Einden \& Hulberts, 2008). Parental drinking on the other hand was related to more frequent heavy drinking by adolescents, illustrating the power of parental modelling.

Similarly, in a Taiwanese study, an important factor in the development of alcohol use in adolescent boys was paternal drinking (Yeh, Chiang, \& Huang (2006). As mentioned earlier, sibling substance use also predicts the likelihood of an adolescent using alcohol to cope with stressful life events; as would be expected, drinking to cope with stressors predicts both alcohol use and alcohol-related problems (Windle, 2000). Also, adolescents in families where a sibling was a drug user, were more likely to be involved with substance-using peers, and to use alcohol as well as other illicit substances. Studies such as this one reinforce the importance of siblings to alcohol and drug use in adolescence.

Researchers in the same Taiwanese study mentioned earlier, saw deviant selfimage as the real factor related to problem drinking in boys (Yeh et al., 2006). Selfimage is also likely to be a result of parenting practices and other researchers have noted that socialization processes play an important role in teens' initial use of alcohol or cigarettes (Duncan et al, 1995; Ellickson \& Hays, 1991). On the basis of their study, Yeh and colleagues argued that preventive interventions for boys should focus on issues such as managing psychological distress and strengthening self-image.

Catalano et al. (1992) compared predictors of the initiation of drug use across different ethnic groups in America: whites, African-Americans, Asian-Americans and Hispanics. For whites and Asian-Americans, those who used fewer drugs were female, were in families where parents practised proactive family management, and 
had no siblings involved in drug use or delinquency. In addition, children in these families understood that their parents disapproved of their use of alcohol. It seems clear that these factors represent protective influences on adolescents' substance use. For African-American adolescents, strong attachment to parents, and parents having a say in friendships were the important protective factors. The influence of parents on drinking at high school and at college has been supported in a study conducted in Hawaii (Turrisi, Abar, Mallett \& Jaccard, 2011). These researchers have also developed an intervention with parents to help them set more appropriate standards for their adolescents' and young adults' drinking behaviour.

Although many parents think that the heavy drinking of their adolescents is just a phase they are going through and that they will have fewer problems when they are older, studies looking at alcohol-use in the transition from high school do not support their optimism (Toumbourou, Williams, Snow, \& White, 2003; Varvil-Weld et al., 2013). Surveying a sample of 3300 students across four waves of data, Toumbourou et al. found five trajectories of alcohol use through the transition from high school. Those using alcohol weekly or more than once a week during high school continued to use it just as often, and more worrying, the amount of alcohol they drank tended to increase over time toward harmful levels. In other words, more frequent alcohol use during the final year of high school tended to precede potentially harmful alcohol use following high school.

Risk factors for substance misuse in adolescence include anti-social personality disorder, a sensation-seeking personality, family approval of drug use, poor or inconsistent parenting, and emotional and behavioural problems such as conduct disorder, depression or attention-deficit/hyperactivity disorder. Other risk factors include poor social connections either at school or in community groups and, as we have noted before, being involved in a peer group where substance abuse is prevalent (Bonomo \& Proimos, 2005).

In line with these findings, Fagan, Van Horn, Hawkins and Jaki (2013) used Social Control Theory to explore the effects of parental controls on adolescent substance abuse. They had students report on their use of five different substances: smokeless tobacco, cigarettes, alcohol, inhalants and marijuana. They assessed three types of parental management strategies: Poor Family Management, Parental Approval of Drug use and Parental Disapproval of Drug use. These researchers found that where parental controls were weak, these $10^{\text {th }}$ grade students were likely to be engage more in drug use, with males and Caucasians most likely to be involved. In addition, those who lived in communities that were seen as favourable to drug use and those with drug-using peers were more likely to be using drugs themselves. There was no attempt in this study to differentiate between the five different substances, some of which are illegal.

In a Spanish study (Jimenez-Iglesias, Moreno, Rivera \& Garcia-Moya, 2013), the focus was on tobacco, alcohol and cannabis and their use across three age-groups of teenagers. In addition, to further test findings that authoritative parenting is related 
to lower substance use, they assessed the important dimensions of authoritative parenting (affection, promotion of autonomy, family activities, solicitation, disclosure and knowledge), and also distinguished between maternal and paternal dimensions. All of these dimensions were significantly related to the use of all three substances. They also found that parents' knowledge of what their adolescents were doing was very important for protecting adolescents from substance use along with quality parent-adolescent relationships that were affectionate, close and communicative.

\subsubsection{Smoking}

There seem to be two primary factors related to adolescents taking up smoking: parental influence and peer influence (Holub, Candelaria \& Laniado-Laborin, 2006). In their "Healthy Generations" study, however, these researchers found that even parents who are aware of smoking-prevention strategies do not necessarily use them with their own children. Some of the strategies suggested include talking with children about the harmful effects of smoking on their bodies, teaching them to say "No" when offered cigarettes or other drugs, keeping them occupied with sport and other healthy activities so they are not hanging around with lots of time on their hands, and knowing who their adolescents' friends are and what they do together.

A review of 87 studies (Avenoli \& Merikangas, 2003) found only weak and inconsistent links between parent and adolescent smoking, but stronger links between sibling and peer smoking and smoking by adolescents. In another review of 27 studies examining the onset of smoking, the factors related to adolescents starting smoking included bonding with peers who smoked, a lack of self-efficacy about their ability to refuse a cigarette when offered, and low self-esteem (Conrad, Flay \& Hill, 1992).

\subsubsection{Risk and Protective Factors for Smoking}

Lewinsohn and colleagues (Lewinsohn, Brown, Seeley \& Ramsey, 2000) compared four groups of adolescents: never smokers, experimenters, frequent smokers and persistent smokers. There were few differences between never smokers and experimenters, smokers (compared to non smokers) scored significantly higher on most measures of psychological dysfunction. Both frequent and persistent smokers had been involved with other drugs and tended to have more friends who smoked. Persistent smokers were more likely to be in conflict with their parents and to be doing poorly academically. Frequent smokers were more likely to be high in impulsiveness, suggesting a lack of self-control.

Griffin and colleagues (Griffin, Botvin, Doyle, Diaz \& Epstein, 1999) found that a number of risk and protective factors measured during early adolescence were related to heavy smoking in a sample of high school seniors. Risk factors included poor grades, experimentation with smoking and alcohol, having a mother who smoked or 
many friends who smoked and being a high risk-taker when they were in $7^{\text {th }}$ grade. Protective factors against heavy smoking included having parents and friends who had strong anti-smoking attitudes and having such attitudes oneself. Unfortunately, this finding only applied to the girls in the sample.

Adolescents with a family history of smoking had more negative expectancies about smoking and, as a result, were less likely to start smoking, but this effect was not present for those with no family history of smoking (Khoddam \& Doran, 2013). These authors suggest that adolescents who notice the negative effects of smoking or who are warned about those negative effects by their parents are less likely to take up the habit.

A study of $8^{\text {th }}$ grade students (Adamczyk-Robinette, Fletcher \& Wright, 2002) found a link between authoritative parenting (assessed using measures of parents' warmth, family structure and the granting of psychological autonomy) and lower levels of tobacco use. This association was also affected by the extent of tobacco use among peers. The lowest levels of tobacco use were among those young people in families where authoritative parenting was practised and who belonged to peer groups that did not smoke. These factors are clearly protective against adolescent smoking. (See Chapter 3 for more discussion of authoritative parenting.)

In another study involving authoritative parenting, Pierce and colleagues (Pierce, Distefan, Jackson, White \& Gilpin, 2002) assessed whether the marketing practices of the tobacco industry actually undermine the positive effects of authoritative parenting. They followed up young people whose susceptibility to tobacco advertising had been assessed three years earlier. They found that adolescents with authoritative parents were overall less likely to smoke than those whose parents used other forms of parenting. On the other hand, those with authoritative parents who were highly susceptible to tobacco advertising were much more likely to smoke than those who were less receptive to advertising. Thus it seems clear that tobacco advertising does undermine the effects of authoritative parenting on the likelihood of adolescents taking up smoking. (see Table 6.2) The Australian Government has already severely curtailed the advertising of cigarettes and has introduced plain-packet marketing of cigarettes as a way of discouraging smoking.

Table 6.2: Risk and Protective Factors Related to Heavy Smoking

\begin{tabular}{ll}
\hline Risk factors & Protective factors \\
\hline Having a mother who smoked & Parents with strong ant-smoking attitudes \\
Having friends who smoked & Friends with strong anti-smoking attitudes \\
Experimenting with alcohol and smoking & Having strong anti-smoking attitudes oneself \\
Poor grades & Authoritative parenting style \\
Being a high risk taker & Constructive family communication \\
Low self-esteem and self-efficacy & Good health practices \\
High impulsiveness & Involvement in organized groups and religious practices \\
Conflict with parents & Positive role models \\
\hline
\end{tabular}


A further range of factors protecting young people from taking up smoking has been labelled developmental assets (Atkins, Oman, Vesely, Aspy \& McLeroy, 2002). This group of researchers tested ten developmental assets: constructive family communication, positive peer role models, future aspirations, responsible choices, community involvement, cultural respect, good health practices, use of time in organized groups and religious activities, and role models other than their parents. Those young people who possessed at least nine of these assets were significantly less likely than those with low levels of assets to report smoking, even after controlling for age, race, gender, parental income and education, and family structure. These findings seem to indicate that these developmental assets protect young people from becoming involved in risky behaviours, particularly smoking.

\subsubsection{Issues Around Sexuality}

\subsubsection{Sexual Activity}

A number of factors have been shown to affect the age at which young people have their first experience of sexual intercourse. Factors such as culture, demographic variables and wealth have been shown to have an impact (Bobakova, Geckova, Klein, Van Dijk, \& Reijneveld, 2013). According to these Slovakian researchers the timing of the first sexual experience is critical for future sexual health. Having sex before the age of fifteen is associated with a greater likelihood of sexually-transmitted diseases (Hawes, Wellings \& Stephenson, 2010), early pregnancy (Forhan, Gottlieb, Sternberg et al., 2009), feeling regretful about the experience and having a larger number of sexual partners in the future (Hawes et al.). In the study by Bobakova et al. peer influence and a lack of parental bonding and monitoring were the key predictors of early sexual initiation.

According to a 2002 survey of American high school students (Auslander, Rosenthal \& Blythe, 2006), almost half of students aged between 15 and 19 were sexually active, with the percentage of sexually-active students aged between 18 and 19 rising to 70 percent. Fewer adolescents under 15 reported being involved in sexual activity, but around 20 percent reported having had sex before they turned 15 .

Mothers' perceived approval of their adolescents' sexual activity was related to unhealthy sexual activities in a sample of American Asian and Pacific Islanders (Hahm, Lee, Zerden, Ozonoff, Amodeo \& Adkins, 2008). Those who perceived their mothers as approving of their sexual activity were more likely to have engaged in sex before they turned 15, to have had multiple sex partners, to have paid for sex and to have contracted an STD.

The quality of parental communication with their adolescents about sexuality along with high quality parent-child relationships tends to promote healthy sexual behaviour. Adolescents from close families where parents monitor adolescents' behaviour, talk openly about sexuality and make their adolescent aware of their disapproval of early sexual involvements (what might be called authoritative families) 
are more likely than those from controlling or permissive families to delay sexual activity and to protect themselves from the possibility of teenage pregnancy or sexually transmitted diseases (Auslander et al., 2006; Bobokova et al., 2013; Sieving, McNeely \& Blum, 2000). The better communication adolescents have with their parents about their everyday lives, the more likely they are to discuss contraception or risks such as STDs with a partner before having sex for the first time (Ryan, Franzetta, Manlove \& Holcombe, 2007). Perhaps the communication skills they learn in interaction with their parents enable them to raise such sensitive issues with a partner (see Chapter 4). The evidence is that the prevalence of sexually-transmitted diseases among adolescents is steadily increasing whether the focus is on Chlamydia and gonorrhoea or on HIV/AIDS (Mule et al., 2009).

\subsubsection{Sex Education and Contraception}

Two of the crucial areas around sexuality for parents of adolescents, as they have always been, are concerns about conception and concerns about infection. These concerns are only magnified by the failure of many sexually-active young people to use contraception, and the problem of sexually-transmitted diseases. Whereas adolescent males in particular report little communication about sex from parents, the messages they do receive tend to focus on abstinence and contraception (Epstein \& Ward, 2008). Messages from peers and the media, on the other hand, tend to encourage sexual exploration. The desperate nature of the sexual activity often shown in movies and TV series would not encourage adolescents to stop and do something about contraception, or even to think about whether they really want to have sex. If young people felt free to discuss issues around sexual activity with their parents there would presumably be fewer adolescents ignorant about this important issue.

The prevalence of teenage births (that is, not counting abortions etc.) is particularly high in the United States, compared with other developed countries. The US teenage birth rate is about nine times higher than in other European countries such as The Netherlands, Sweden and Switzerland, triple the rate in Canada and one and a halftimes that in the UK (Pazol, Warner, Gavin, Callaghan et al, 2011).

Religious factors also play a part, with conservatively religious adolescents and those who feel guilty about having sex being less likely to be sexually active but also less likely to use contraception if they do have sex (Bearman \& Bruckner, 2001; Miller \& Gur, 2002). Being the firstborn in the family and being consistently involved in religious activities distinguished those who had not had sex by age 21 in a large NZ study, particularly for men (Paul, Fitzjohn, Eberhart-Phillips, Herbison \& Dickson (2000). For women, other factors seem to come into play, such as not being in love enough, fear of pregnancy and moral and religious beliefs (Sprecher \& Regan, 1996). Parent religiosity also plays a part, with frequent parental attendance at religious activities and encouragement of family religious activities related to later onset of sexual activity. 


\subsubsection{Pregnancy and Childbearing}

Although it seems clear that more than one and a half million pregnancies are avoided each year because of young people using contraception (Kahn, Brindis \& Glei, 1999) studies have shown that around 20 to 30 per cent of young people report not using contraception the last time they had sex (Coleman, 1999, Hogan et al., 2000). As noted earlier, rates of teenage pregnancy are substantially higher in the USA than in other industrialized countries and this seems to be a result of American adolescents not using contraception regularly or effectively (Darroch, Singh \& Frost, 2001), the sexsaturation of American media, the way non marital sex is presented as exciting and titillating (Jones et al., 1987) and the failure of the media to deal effectively with the issue of contraception (Westoff, 1988), or presenting it as "a necessary but disagreeable responsibility" (Carpenter, 2001, p.47). Although adolescents who reported wanting to avoid pregnancy were more likely to use contraception when having sex than those who were not trying to avoid pregnancy, only about half of the sex engaged in by the former group was protected by contraception (Bartz, Shew, Offner, \& Fortenberry (2007). These findings seem to suggest a lack of understanding of the importance of contraception to avoiding pregnancy and disease or reflect the adolescent stage of brain development, where it is difficult to make considered decisions in social situations with peers (see Chapter 1).

\subsubsection{Conduct Disorder, Antisocial Behaviour, Aggression and Delinquency}

\subsubsection{Conduct Disorder}

Conduct disorder is a repetitive and persistent pattern of behaviour in which the individual ignores and even flouts the basic rights of others by hurting them or their property. It can also involve violating the socially appropriate rules for one's own age group, such as rules about drinking alcohol, driving a car or truanting from school (Flannery, Hussey, Biebelhausen \& Wester, 2003). Although in the minority, it is indicated that at any particular time, between 6 and 16 percent of adolescent males and between 2 and 9 percent of adolescent girls have a diagnosis of conduct disorder (Farrington, 1994). Whereas girls tend to have low levels of conduct problems that are stable over time, boys tend to have either high levels of conduct problems that are stable over time or decreasing levels of conduct problems (Maughan, Pickles, Rowe, Costello \& Angold, 2000). Conduct disorder generally follows from oppositional defiant disorder (ODD), with such symptoms as temper tantrums and defiant, irritable and argumentative behaviour (Hinshaw, Lahey \& Hart, 1993). Obviously these kinds of behaviours are likely to have a negative impact on the small number of families likely to be affected.

There is evidence that particular styles of parenting can help youths engaged in antisocial behaviour to change. Parenting that is characterized by monitoring of peer contacts so that interactions with deviant peers are minimized, and that involves the 
setting of firm limits, consistent consequences for inappropriate behaviour, close supervision of youth activities and positive interactions between the youths and those caring for them can make a real difference to the lives of young people and even lead to the young person decreasing their antisocial behaviour (Eddy \& Chamberlain, 2000).

\subsubsection{Aggression and Antisocial Behaviour}

Aggression is defined as behaviour that intentionally harms another person (Coie \& Dodge, 1998; Farrington, 2004). Such aggression can be physical (such as hitting), verbal (such as calling names or putting down) or psychological (intimidating, or causing fear or distress). Behaviour such as bullying could involve all three of these aspects of aggression. While bullying is fairly common in elementary school, it tends to decrease through high school (Farrington, 2004). Whereas some have argued that aggression is a stable personality trait (e.g., Olweus, 1979), others suggest that children learn aggressive scripts through the pattern of rewards and punishments in their families and that these scripts are then played out in their relationships in other contexts (Huesmann \& Eron, 1989). With the introduction of the internet and social sites such as YouTube and Facebook, and the prevalence of mobile phones with cameras, an alarming trend has developed, at least in Australia, with peers photographing incidents of bullying and then putting the photos on the internet for all to see.

The danger is that aggression in children and adolescents tends to evoke negative parenting, and this negative parenting, including hostility, harshness, neglectfulness, rejection and conflict can lead to adolescent antisocial behaviour (Herrenkohl, Maguin, Hill, Hawkins, Abbot, \& Catalano, 2000; Narusyte, Andershed, Neiderhiser \& Lichtenstein, 2007; Shaw, Gilliom, Ingoldsby, \& Nagin, 2003). There is clear evidence that parental negativity precedes changes in adolescent antisocial behaviour (Burt, Donnellan, Iacono \& McGue, 2011; Burt, McGue, Krueger, \& Iacono, 2005; Morgado \&Vale-Dias, 2013; Neiderhiser, Reiss, Hetherington \& Plomin, 1999). In other words, parental negativity seems likely to cause the development of antisocial behaviour in at least some children and adolescents.

Antisocial behaviour can involve such behaviours as lying or underage alcohol consumption to more serious behaviours such as animal cruelty, theft and assault (Murgado \& Vale-Dias, 2013). Many different factors can contribute to antisocial behaviour, including individual characteristics, social environment and family characteristics. In a study using a large Spanish sample of secondary-school students (Jaureguizar, Ibabe \& Straus), positive family relationships were related to more prosocial and less violent actions towards parents, whereas antisocial and criminal behaviour were positively related to violence towards parents. These three variables, including negative family relationships were also related to violence against teachers, illustrating that the effect of family relationships goes way beyond the home. 


\subsubsection{Delinquency}

Delinquency is "a legal term defined as criminal behaviour committed by minors" (Flannery et al., 2003, p.502). Delinquent behaviours include theft, robbery, burglary, violence of various kinds, vandalism and drug use; in short, any acts prohibited by the criminal code (Farrington, 2004). Studies in both the U.K. (Farrington, 1989) and in the USA (Loeber, Farrington, Stouthamer-Loeber, Moffitt, \& Caspi, 1998) have shown that self-reported delinquency predicts later convictions and court referrals. In other words, adolescent delinquency can set young people on a criminal trajectory, although fortunately many will cease delinquent behaviour before reaching adulthood (Stouthamer-Loeber, Wei, Loeber \& Masten, 2004).

Predictors of delinquent behaviour at a young age include having authoritarian parents, being troublesome at school and truanting, rarely spending leisure time with the father, being in a peer group that engaged in delinquency and being poorly supervised by parents (Farrington \& Hawkins, 1991; Loeber, et al., 1998). Personality characteristics that predict delinquent behaviour include impulsiveness, physical aggression, being oppositional, defiant and hyperactive (Farrington \& Hawkins, 1991; Loeber et al., 1998).

What these findings consistently show is that authoritative parenting, appropriate levels of monitoring, being engaged with children and adolescents and assisting them to regulate their emotions protects young people from becoming involved in a range of problematic behaviours. In other words, positive parenting and a caring family environment promote healthy adolescent development.

\subsection{Internalizing Behaviours}

\subsubsection{Depression}

Research findings suggest that about 3 to 8 percent of adolescents are likely to suffer from depression while still in school and that about 20 percent will have experienced a depressive episode by the time they are 18 (Lewinsohn, Rohde, Seeley \& Fischer, 1993). In addition, a lot of adolescents experience symptoms of depression that are not serious enough to be diagnosed, but that nevertheless can have an impact on both their present and later well-being. Before the onset of puberty, both boys and girls are equally likely to experience depression (Nolen-Hoeksema \& Girgus, 1994), but around the age of 15, girls become much more likely to experience depression than boys (Hankin, Abramson, Moffitt, Silva et al., 1998), although the reasons do not seem to be well understood.

Depressed adolescents tend to come from homes where there is a lot of conflict and distress (Seroczynski, Jacquez \& Cole, 2003), or from divorced or father-absent homes (Shiner \& Marmorstein, 1998). A number of family-related factors affect the likelihood that an adolescent will become depressed, including parental depression, coercive 
family processes, absence of supportive and facilitative interactions, depressive or pessimistic thinking styles, ineffective problem-solving skills and lack of skills for dealing with emotion (Sheeber, Hops \& Davis, 2001). In fact, family relationships tend to be better predictors of adolescent depression than are relationships with peers (McFarlane, Bellissimo, Norman \& Lange, 1994; Sheeber, et al., 2001).

It seems likely that parenting behaviour is a major way that parental psychopathology, marital problems, negative life events and financial hardship come to be linked to depression in children and adults (Sheeber et al., 2001; see Table 6.3). It makes sense that parents who are struggling with such issues as marital conflict or financial difficulties will lack the energy and the will to parent effectively. Good parenting takes both time and energy. In a recent study (Lewis, Collishaw, Thapar \& Harold, 2013) the researchers found that mother-daughter hostility was a strong predictor of adolescent depression, and that this effect was both longitudinal and reciprocal. In other words earlier hostility predicted later depression, and both mothers and daughters were affected, suggesting an increasingly destructive family environment for both mothers and daughters. In contrast, depressive symptoms displayed by daughters increased father hostility toward that daughter, but the effects were not reciprocal. There was evidence, however, in the part of the study that involved twins, of a genetic component to the depressive symptoms.

In a study of the effects of positive and negative family emotional climate on the internalizing disorders (depression and anxiety) of adolescents (Luebbe \& Bell, 2013), there was evidence that in a family environment in which maternal psychological control was high, adolescents were more likely to experience anxiety and depression and this link was mediated by negative emotion. On the other hand, in a family environment where mothers were not very warm and little positive emotion was expressed or experienced, adolescents were more likely to be depressed.

In another study of family functioning and adolescent internalizing disorders using a longitudinal prospective design (Sheidow, Henry, Tolan \& Strachan, 2013), the researchers found that family functioning was the mediator of the association between stress from daily hassles and internalizing symptoms such as depression. Their measure of family functioning involved assessing both family relationships and family functioning. Thus, it seems that where adolescents are subject to frequent stress, problematic family functioning predicts depression and anxiety.

In a study of Mexican adolescents (Gil-Rivas, Greenberger, Chen, Lopez-Lena, 2003), gender (that is, being female), having a perception that one has experienced many stressful life events, and having a tendency to ruminate about those stresses were related to being more depressed. On the other hand, lower levels of depression were related to higher levels of perceived warmth and acceptance from parents, as well as higher levels of parental monitoring. Thus both family factors and individual factors seem to contribute to depression in adolescents. In addition, where parental warmth and acceptance were at high levels, adolescents were less likely to ruminate on their problems. 
Table 6.3: Risk and Protective Factors Related to Depression

\begin{tabular}{ll}
\hline Risk factors & Protective factors \\
\hline High levels of family conflict & Supportive family interactions \\
Divorce or father absence & Effective problem-solving skills \\
Parental depression & Skills for dealing with emotion \\
Coercive family processes & Authoritative parenting \\
Pessimistic thinking styles & Self-confidence in ability to make decisions \\
Negative life events & Age-appropriate autonomy \\
Financial hardship & \\
\hline
\end{tabular}

\subsubsection{Effects of Parental Depression}

There is evidence that depressed mothers are more aggressive than other mothers in family interactions in the laboratory and at home, and that their children tend to be more irritable, particularly when the mother is also unhappy with her marriage (Hops et al., 1987). Adolescents who have parents with a history of depression tend to report more symptoms of depression after experiencing a stressful life event than adolescents whose parents are not prone to depression (Bouma, Ormel, Verhulst, \& Oldehinkel, 2008), and this effect seems to be stronger for girls, perhaps because they tend to be more sensitive to stress. The likelihood that adolescents whose parents have a history of depression will also become depressed is affected by the amount of family conflict (Davies \& Windle, 1997) and by the temperament of the adolescent (Ormel et al., 2005) (see also Chapter 3).

\subsubsection{Coercive Family Processes}

As would be expected given the findings of Lewis et al. (2013) reported earlier, both depressed adolescents and their mothers describe their family interactions as more conflicted, more negative and involving more openly-expressed anger than is true for non-depressed adolescents (Sheeber \& Sorensen, 1998), although it is not always clear whether the depression precedes the coercive family processes or the other way around. In addition, less supportive and more conflictual family environments produce increased depressive symptoms concurrently and up to a year later (Kendler et al., 2002; Reinherz et al. 2002; Sheeber, Hops, Alpert, Davis \& Andrews, 1997). When parents are hostile to their children and use harsh discipline, the risk of those children developing internalising disorders such as depression and anxiety is increased (Conger, Ge, Elder, Lorenz \& Simons, 1994; Sheeber et al.,1997).

In a study designed to test the association between genetic factors and family conflict in predicting depression in children and adolescents Rice et al. (Rice, Harold, Shelton \& Thapar, 2006) found that the effect of being at genetic risk for depression 
was particularly strong when the family environment was high in conflict. In other words, adolescents living in high conflict families with a history of depression are particularly likely to become depressed themselves. These findings are also in line with those of Lewis et al. (2013). Rice et al. (2013) suggest that interventions that involve the family are most likely to be of help to young people living in this type of family.

\subsubsection{Supportive and Facilitative Interactions}

Contented adolescents seem to live in family environments that are higher in terms of nurturance and support than the environments experienced by depressed young people (Sheeber \& Sorensen, 1998). Mothers of contented adolescents tend to be helpful and cooperative with their adolescents during problem-solving discussions. According to Sheeber et al. (2001) one of the most widely-reported findings about adolescent depression is that the more support and approval provided to the adolescent and the more secure their attachment to parents, the less likely they are to become depressed.

\subsubsection{Life Skills and Depression}

Life skills tend to be learned in the family and include having an optimistic rather than a negative way of thinking about oneself and the world (Seligman, 1991), being able to solve problems effectively and being able to control one's emotions. When mothers are very critical of their adolescents, the adolescents are more likely to develop a negative view of themselves (Jaenicke et al., 1987). In addition, fathers' critical statements tend to be related to adolescents' self-denigrating comments during problem-solving discussions (Hamilton, Asarnow \& Thompson, 1999). In other words, both parents contribute to the development of depression in adolescents, if they are very critical. In an observational study, when mothers responded to adolescent aggression with aggression or were seen to suppress their aggression in response to adolescents' distress, the adolescents were more likely to suffer from a major depressive disorder at a later time (Allen, Hauser, O’Connor \& Bell, 2002; Schwartz, Dudgeon, Sheeber, Yap, Simmons, 2011). As indicated in Chapter 4, it is evident that families that engage in constructive problem-solving teach their adolescents to deal with conflict in positive ways and protect them against the onset of depression.

Parents who tend to control their adolescents by inducing guilt or a strong sense of responsibility for others are also likely to increase the probability that their adolescents will become depressed (Donenberg \& Weisz, 1998; Garber, Robinson \& Valentine, 1997). On the other hand, where parents and adolescents have very supportive relationships, adolescents are more likely to develop higher self-esteem and a greater confidence in their ability to cope (Hoeltje, Zubrick, Silburn \& Garton, 1996). 
A second aspect of life skills is problem-solving. When parents are authoritarian in their approach to their children and adolescents, their adolescents are likely to have fewer opportunities than others to develop age-appropriate autonomy, especially if their participation in family decision-making is also limited, with consequent increases in depression (Allen, Hauser, Eickholt, Bell \& O'Connor, 1994). The older the adolescents are, the more likely that having limited autonomy and little say in family decision-making will increase their risk of depression (Kobak \& Ferenz-Gillies, 1995) because they have less opportunity to develop selfconfidence in their ability to deal with problems that arise. (see Chapter 4 for more discussion of decision-making).

Depressed adolescents also seem to have a quite limited repertoire of strategies for managing negative effect. In addition, the strategies they have tend to be less effective and they often fail to make use of those strategies because of their low expectations for success (Garber, Braafladt, \& Weiss, 1995). For example, they are less likely to use positive strategies such as problem-solving or reframing, and more likely to use avoidance responses (like running away from the situation) or ruminating (going over and over the issue in their heads). There is also evidence that during parentadolescent interactions, depressed adolescents maintain negative mood states longer than other adolescents (Sheeber, Allen, Davis \& Sorensen, 2000).

As we have noted earlier in this volume, adolescents have to face and resolve a number of developmental tasks or challenges, and "successful negotiation of each task results in a healthier psychological system better prepared to meet the demands of the next developmental challenge" (Seroczynski et al., 2003, p.552). According to these authors, depression could be seen as an unsuccessful response to these developmental challenges; that is, giving up rather than persevering with difficult challenges.

\subsubsection{Self-harm and Suicide}

According to the Centres for Disease Control and Prevention (2013), suicide is the third most common cause of death in adolescents and young adults, at least in the USA. Tynan (2013) argues that many suicides are not recognized as such, but are seen as accidents suggesting that the situation is even worse than the statistics suggest.

Adolescents who deliberately harm themselves by such behaviours as cutting their wrists or taking an overdose of drugs are less likely than other adolescents to report having good communication with family members or feeling understood by them (Shaffer, Gould, Fisher, Trautman et al., 1996). In a large sample of 15 and 16 year old high school students in England, about 7 percent reported that they had deliberately harmed themselves during the previous year, whereas another15 percent had thoughts about hurting themselves but did not do anything (Hawton, Rodham, 
Evans \& Weatherall, 2002). In the same sample, the number of adolescents who felt that they needed help because of their problems but did nothing about getting that help was greatest in those who had harmed themselves at least once (Evans, Hawton \& Rodham, 2005).

Another characteristic of this group was that they tended to avoid rather than deal with issues in their lives. As we have discussed above, not being able to deal with problems as they arise is an important predictor of depression, especially for adolescents from authoritarian families who have had little opportunity to develop the necessary problem-solving skills (Evans et al., 2005; Kobak \& Ferenz-Gillies, 1995 In addition about a quarter of the young people who harm themselves think that their problems are not really serious (Evans et al., 2005). It may be that such adolescents need help in identifying and articulating their problems and in assessing how serious they really are (Saunders, Resnick, Hoberman \& Blum, 1994). Being able to talk with their parents about their problems would help them articulate the issues and work through them. The problem with authoritarian families is that the parents are often rigid and unable to see alternative perspectives. It is also possible, of course, that the young people may be denying the very real problems that exist in their lives in order to avoid having to deal with them, and may also, through their past behaviour or because of family problems, have isolated themselves from possible sources of help (Evans et al., 2005).

In an important study into the link between problem-solving skills and suicide attempts, Dour, Cha and Nock (2011) tested the impact of the interaction of emotion reactivity and cognition on suicide attempts in a sample of adolescents and young adults. These researchers found that young people's levels of problem-solving skills affected whether they would react to a highly emotion-inducing event by making a suicide attempt. For those with poor problem-solving skills, their emotional reactivity was strongly associated with the probability of a suicide attempt, and for those with average problem-solving skills, their emotional reactivity was moderately associated with the probability of a suicide attempt. On the other hand, there was no association between emotional reactivity and suicide attempts for those who had learned good problem-solving skills in their families.

Nonsuicidal self-harm has been shown to be a better predictor of suicide than a previous suicide attempt (Wilkinson, Kelvin, Roberts, Dubicka \& Goodyer, 2011). Brent (2011) argues that for this reason, self-harm needs to be taken more seriously by practitioners, especially when dealing with clinical adolescents, where the link is much greater than in community samples. Brent also points out that self-harm and suicide attempts have similar causes including low frustration tolerance, and a tendency to engage in self-critical cognitions along with a sense of hopelessness and high levels of suicide ideation (Wilkinson et al.). Parents would also seem to have a role here, in taking self-harming seriously and helping their adolescents talk about their issues. Given that self-critical comments are likely to be a result of 
negative parenting, interactions with disturbed young people will need to be high on affirmation and low on criticism.

Although suicide and suicide attempts can be a result of psychiatric illness, family factors have also been implicated. A number of recent studies have found an association between family dysfunction and depression and suicidal behaviour (Gould et al, 2003; Hurd \& Noller, 2012; Kuhlberg et al., 2010). In the Hurd and Noller (2012) study, most depressed or self-harming adolescents reported receiving low levels of care in their families. Many of the clinical adolescents reported that the parenting they received was low in care and high in control (generally described as affectionless control). The lack of care reported by these adolescents could mean that they are unlikely to receive the support, guidance, and appropriate limits they need in order to be able to negotiate autonomy at an age-appropriate level. According to Sheeber et al. (2001), parenting behaviours are important because it is through parents' interactions with their offspring that psychopathology, marital problems, negative life events and financial hardships come to be linked to depression in children and adults.

Factors such as separation from a parent or a family divorce have already been mentioned as risk factors for depression, but they are also risk factors for suicidal behaviour, with about 50 per cent of suicidal adolescents coming from divorced or single-parent families (Allberg, 1990). Nevertheless, patterns of family functioning and family psychopathology are even more important than family structure (Wannan \& Fombonne, 1998). It is possible that the trauma and distress of separation and divorce lead to destructive patterns of family functioning as well as parental depression and substance abuse.

For example, there is some evidence that the families of suicidal adolescents tend to involve a lack of cohesiveness (Sheftall, Mathias, Furr \& Dougherty, 2013) along with conflict, chaos and unpredictability (Robbins, 1998). As Hurd and Noller (2012) found, these families are also often low in affection and enjoyment (Stillion \& McDowell, 1996). Another relevant family factor is a lack of paternal attachment (Sheftall et al. 2013) as well as a history of childhood sexual or physical abuse (Robbins, 1998), often because abused adolescents develop psychiatric illnesses such as depression in response to the abuse (Bayapour, Wells \& Holoford, 1992).

It also seems clear that child maltreatment is a strong predictor of adolescent suicide and self-harming, whether this maltreatment is sexual, physical, emotional or involves neglect (Miller, Esposito-Smythers, Weismoore \& Renshaw. 2013). These researchers found that the links between these different forms of maltreatment and suicidal behaviour were maintained even when controls for demographic and family-related variables were included. Interestingly, there was also evidence that the different forms of child maltreatment are independently associated with suicidal behaviour with sexual and emotional abuse making the strongest contribution. 


\subsubsection{Eating Disorders}

There are a number of eating disorders to which adolescents are prone, including the well-known anorexia nervosa, bulimia nervosa, binge-eating disorder and obesity. In a study carried out in the USA (Hudson, Hiripi, Pope \& Kessler, 2007), $9 \%$ of females in the sample were affected by anorexia nervosa, $1.5 \%$ were affected by bulimia nervosa and 3.5\% were diagnosed with binge eating issues. For males, the figures were much lower.

Other researchers suggest that thelikelihood of developing serious eating disorders is much lower. For example, Vedul-Kjelsas (2005) claims that anorexia nervosa is generally lower than 1 percent, that bulimia nervosa also occurs in just over 1 percent, and that binge-eating disorder occurs in about 1.5 percent. Given the discrepancy between these figures and those for USA presented earlier, it seems that the prevalence of serious eating disorders depends on the population being studied. It is also clear that girls are much more likely to develop eating disorders than boys. According to (Beato-Fernandez, Rodrigues-Cano, Belmonto-Llario \& Martinez-Delgado, 2004) girls are up to seven times more likely than boys to develop a pathological dissatisfaction with their bodies, perhaps as mentioned earlier, because of the emphasis on thinness in the media and the frequent use of skinny models by advertisers (Garner, 1997). Another factor according to Manley and Leichner (2003) is a loss of voice by young women. They suggest that girls may be socialized to meet the needs of others, but are less able to identify and express their own emotions in helpful ways.

A number of individual and family factors have been associated with the development of eating disorders, including early eating disturbances (Kotler, Cohen, Davies \& Walsh, 2001), over-concern about weight and shape (Killen, Taylor, Hayward, Haydel et al., 1996), perfectionism and negative emotion (Tyrka, Waldron, Graber \& Brooks-Gunn, 2002), low self-esteem, perceived lack of social support, use of escape-avoidance coping, and preoccupation with being thin (Beato-Fernandez et al., 2004; The McKnight Investigators, 2003). All of these factors are associated with an increased risk of developing an eating disorder, with the disorder likely to last for six or more years (Manley \& Leichner, 2003), presuming the teenager lives that long.

In an Australian study exploring the influence of parental modelling and encouragement on dieting and body dissatisfaction (Wertheim, Martin, Prior, Sanson \& Smart, 2002), mothers and fathers and sons and daughters were included in the sample. These researchers found that parental encouragement was a more important influence on the dieting behaviour of adolescents than was parental modelling. In addition, these researchers found no selective pressures related to sex of parent or sex of child. "Mothers and fathers were equally likely to be described as encouraging their child, and sons and daughters were equally likely to be encouraged by their parents to lose weight” (p.329). A worrying aspect of their findings was that adolescents whose parents were encouraging them to lose weight were more likely to be dissatisfied with 
their bodies and to value thinness, although this kind of pressure was mostly, but not always, applied to larger children. These issues are concerning in a culture where there are high levels of obesity and there is a lot of emphasis in the media on losing weight. In terms of family factors, childhood difficulties and maladaptive parenting behaviour on the part of fathers have also been implicated (Johnson, Cohen, Kasen \& Brook, 2002).

Having an unsatisfactory relationship with one's parents, disliking one's mother, perceiving one's parents as not loving enough, or believing that one is ignored by them (Beato-Fernandez et al., 2004) are all factors related to the development of eating disorders. In the Beato-Fernandez study, 13-year old girls who were dissatisfied with their body (shape and weight) and felt that they were not loved enough by their mothers were three times more likely than other adolescent girls to develop an eating disorder in the next two years. In fact, these authors claim that dissatisfaction with their bodies is the most important factor for predicting eating disorders. Parents may not realise how much their comments about the weight or shape of their adolescent daughter, however subtle, can have a serious impact on those young people.

Lampi, Agus and Cacciarru (2013) explored the effects of family functioning on the likelihood of developing an eating disorder. They focused on individual factors such as the desire for thinness, dissatisfaction with one's body and family factors such as levels of cohesion and adaptability (Olson et al., 1983) in the family and levels of care and protection from parents. These researchers found that affectionless control (in other words, low levels of parental affection combined with high levels of control) was related to the development of eating disorders. Lack of family cohesion was also found to play an important role in the development of discontent with body image.

Holtom, Viesel and Allan (2013) carried out a systematic review of the literature on family functioning and eating disorders where families with an adolescent with an eating disorder were compared with a control group. They found that families with an eating-disordered adolescent were more likely to report family dysfunction than control families but these researchers were unable to identify a particular pattern of family dysfunction that predominated in these families. In addition they were not able to find a consistent link between a particular family issue and a particular type of eating disorder.

Marcos, Sebastian, Aubalat, Austin and Treasure (2012) carried out a metaanalysis of studies on peer and family influences in eating disorders. One interesting aspect of the study was that they included studies involving both boys and girls. They found that both family and peers had a significant impact on dieting behaviour and body dissatisfaction for boys as well as girls although there were gender differences in the impact of peers. Girls were more influenced by peers with regard to dieting behaviours than were boys. Vincent and McCabe (2000) argued that girls are more likely to talk about personal issues such as dieting and weight loss than are boys. In addition, boys are not so influenced by the ideal of thinness that is promoted by the fashion industry and the media generally. Increased levels of maternal and paternal 
caring, and of family cohesion and adaptability (flexibility) lessened the risk of developing an eating disorder. Nevertheless it is concerning that both boys and girls are susceptible to developing eating disorders even though girls are the major focus of research.

It seems that there is a progression in the development of eating disorders. For example, an over-concern about eating, weight and body shape in combination with low self-esteem can lead to strict dieting, even trying to follow rigid and unrealistic diets. Failure to keep to such a regime is likely to be interpreted by the young person as an inability to control eating and make them vulnerable to binge-eating. Then, to compensate for the binge-eating, they are likely to get involved in the vomiting and purging (by using laxatives) that are a feature of bulimia-nervosa. The binge-eating can then increase their over-concern about eating, weight and body-shape, and lead to even greater restrictions on eating and a progression to anorexia nervosa, a condition that can be fatal (Byrne \& McLean, 2002; Decaluwe \& Braet, 2005, Fairburn, Stice, Cooper, Doll et al., 2003). It is interesting to note that childhood obesity is also a risk factor for bulimia-nervosa and binge-eating disorder (Decaluwe \& Braet, 2005).

One important concern about eating disorders is that those who suffer from eating disorders suffer from deep psychological pain (Manley \& Leichner, 2003). For example, self-harming thoughts and behaviours such as self-mutilation and suicide attempts are common among those with eating disorders. Anorexia nervosa has the highest rate of death, partly because of increased risk of suicide and partly because of complications caused by severe malnutrition (Garner, 1997; Mitchell, Pomeroy \& Adson, 1997). On the positive side, there are now, certainly in Australia, and presumably in other Western countries, effective programs that help young people deal with eating disorders, with psychologists, medical doctors and nutritionists involved.

\subsection{Summary}

Many young people become involved with alcohol and illegal drugs. Although alcohol problems are more common than drug problems and are related to many serious issues such as assaults, car accidents and criminal activities, parents tend to worry more about illicit drugs, and don't always demand responsible behaviour from their adolescents with regard to alcohol. When parents do apply strict rules about alcohol, adolescent use tends to be lower.

Peer encouragement of involvement in substance abuse leads to higher levels of use and increasing use of drugs over time. Substance abuse may negatively impact an adolescent's ability to deal with the developmental tasks that need to be negotiated at this stage of life. Adolescents who engage in problem-drinking are more likely to come from families with an alcoholic parent, and tend to be involved in drug-use and other delinquent activities. Alcohol tends to be the starting point for drug abuse 
and adolescents may then move on to cannabis and other illegal drugs. Risk factors for drug abuse include poor or inconsistent parenting, emotional and behavioural problems and being involved in a peer group where drug abuse is prevalent.

The primary concern about the approximately 25 percent of young people who smoke is the serious health consequences of the habit. Only weak and inconsistent links have been found between parent smoking and adolescent smoking, but stronger links are evident between the smoking of siblings and peers and adolescent smoking. Adolescent smokers have been found to score significantly higher on measures of psychological dysfunction, particularly impulsiveness, than non-smoking adolescents. Having parents with anti-smoking attitudes is a protective factor, decreasing the likelihood that an adolescent will smoke.

Almost half of young people between 15 and 19 yrs are sexually active, and by 18 or $19 \mathrm{yrs}, 70$ percent of young people are likely to be involved in sexual relationships. Parents are concerned about their adolescents being involved in sexual activity because of the risks of infection and conception, particularly since young people do not always use contraception. In addition, parents and adolescents seem to be unaware of the extent of the STD problem, even though about a quarter of American adolescents contract a sexually-transmitted disease before they finish high school. Adolescents from authoritative families are more likely than those from controlling or permissive families to delay sexual activity and to use contraception if they do get involved in a sexual relationship. Involvement in religious activity decreases the likelihood of early involvement in sexual activity.

About 20 percent of adolescents are likely to suffer from depression, some while still in high school. Girls are more likely than boys to experience depression particularly post puberty. Factors affecting the chance that adolescents will become depressed include a range of family factors such as high levels of conflict, divorce and father-absence, parental depression, coercive family processes and lack of basic social skills such as problem-solving and emotion regulation. It seems likely that parenting behaviour is the main mechanism for transmitting depression from parent to adolescent.

Although girls are more likely to make suicide attempts and engage in self-harming behaviours, boys are more likely to die as a result of a suicide attempt because they use more lethal methods such as firearms. Those young people who attempt suicide are more likely to avoid rather than deal with issues and less likely to seek help for their problems. Although suicide attempts can be the result of the challenges of adolescence, family factors are also implicated. Such families are likely to be high in conflict, low in cohesiveness, warmth and enjoyment and somewhat chaotic.

Some adolescents are prone to eating disorders such as bulimia, anorexia nervosa, binge-eating and obesity. Individual and family factors associated with eating disorders include over-concern about weight and shape, perfectionism and negative emotions, low self-esteem and perceived lack of social support. Family factors such as level of care by parents and the levels of cohesion in the family are also 
important. Females are most at risk of developing eating disorders, and unsatisfying relationships with parents have also been implicated. There seems to be a progression in the development of eating disorders from strict dieting, to binge-eating to bulimia to anorexia nervosa.

A minority of adolescents become involved in illegal behaviour that hurts others and others' property. Current examples include throwing rocks from an overpass onto the cars below, gate-crashing parties and engaging in violent behaviour, smashing letterboxes as people's homes are passed, and stealing and damaging cars. A lot of this behaviour is fuelled by alcohol. Parents who set firm limits, provide consistent consequences for bad behaviour and who provide adequate monitoring and supervision are less likely to have adolescents who engage in such antisocial behaviour. Of course, aggressive adolescents can evoke negative parenting behaviour but the evidence is that negative parenting tends to precede antisocial behaviour and is the adolescent' response to that type of parenting.

\subsection{Implications for Practitioners}

Given that the family, and particularly parents, are critical to the development of problem behaviour in adolescents, a family approach to dealing with these issues seems important. Parents are likely to need help to develop a parenting style that is authoritative and that shows loving concern for the adolescent, and sets limits at the same time as allowing the age-appropriate level of autonomy and independence to the adolescent. Learning this style of parenting seems crucial to dealing with the various problems that adolescents can come up against.

With regard to alcohol and drug abuse, parents may need help to understand the risks of alcohol abuse in young people and demand responsible behaviour from them. Parents may also need to examine their own behaviour in terms of their own drinking, and also in terms of the behaviour that they are modelling for their offspring. The young people, themselves, may need help with their emotional problems so that the need for drugs is not so strong.

Some monitoring of peer groups may also be important as peers, including siblings, have an impact on the likelihood that an adolescent will become involved in illegal drug use. In terms of smoking, a whole family approach seems necessary, given that there are stronger links between sibling and peer smoking than parent smoking. Adolescents might also need help to deal with such personality problems as impulsiveness that seems to be related to smoking. Having the level of self-esteem that allows young people to say "No" to offers of illicit drugs is also important. Being able to say "No" may be the only protection they have against peer pressure to engage in such illegal activities.

Although it may be difficult in today's climate to prevent early sexual activity in young people, there may be need for parents to set standards for their young people 
beyond the sex on first date culture that seems to dominate the young and often the movies and TV shows they watch. They also need to realise that conception and infection are important consequences of such activity. While these can be dealt with by encouraging the use of contraception, it is not the full answer. Young people seem to need more education about the risks of unprotected sex and about appropriate ways to deal with those risks. The high levels of STDs in American adolescents suggest that help is needed.

Parents with depressed adolescents are likely to need help to provide a family environment that will be positive for their adolescents. Helping parents deal with their conflicts constructively so that these young people are not continually subjected to high levels of conflict between them would provide a more congenial environment. Encouraging them to have regular contact with absent fathers where that is appropriate and helping them to learn some basic life skills such as emotion-regulation and problem-solving should also help. Of course, if the depression is severe, adolescents may need anti-depressive medication or other types of psychiatric help. Learning life skills may also help them to deal more effectively with the challenges they face and less likely to attempt suicide.

Various kinds of therapy and prevention programs have been tried with those with eating disorders, with varying levels of success (Manley \& Leichner, 2003). Treatment that deals with feelings of hopelessness or the faulty thinking that leads to the over-concern with body image and negative attitudes towards food and eating can be useful. Another aspect of treatment might be to help girls develop "a healthy scepticism toward media influences, including their oppressive effects with respect to promotion of harmful and unrealistic body shapes for women” (Manley \& Leichner, 2003, p.34). It may also be important, given the family-related factors involved, for some form of family therapy, or at least family counselling, to be included in treatment (Manley \& Leichner, 2003; Wilson \& Shafran, 2005). Work on family meal patterns may also be important given that in families where meals are a priority time, and meal-times are structured, there seem to be fewer problems involving extreme weightcontrol behaviours (Neumark-Sztainer, Wall, Story \& Fulkerson, 2004).

It may also be important for young people to develop their assertiveness skills so that they can learn to resist requests for them to become involved in inappropriate behaviours such as binge-drinking, using illicit drugs or engaging in unwanted sexual activity. When it comes to the point of adolescents being encouraged by peers to engage in such behaviours, being able to say "No" may be critical. The situation may be similar for such anti-social behaviours as vandalism, stealing cars or driving too fast. Many psychologists play down the importance of adolescents being taught to resist getting involved in inappropriate behaviours, but such an ability may save them from difficult situations and may even save their own or someone else's life. In addition, young people who know how to resist such involvements can be trusted with more freedom than those who go along with that small group of young people who could be labelled "trouble-makers". 
In this chapter we have explored the impact of parental behaviour and family environments on adolescents' involvement in problem behaviours and the potential outcomes of those involvements. In the next chapter we explore the contexts in which adolescents leave the family home and live more independently of their parents' guidance. 